\title{
Design da informação e conteúdo para dispositivos móveis: projeto de website para Instituição de Ensino Superior, IES, adaptado para iPad.
}

\author{
Design information and content to mobile devices: website project for Higher \\ Education Institution, IES, adapted for iPad.
}

Tiago Zambuzi Sanches, Tomas Guner Sniker

design de interface, aplicativos móveis, tablets, web design

\begin{abstract}
O acesso instantâneo de informações e o desenvolvimento de tecnologias de comunicação móveis ocasiona uma potencialização dos modos de interatividade. A criação e a popularização dos tablets apresentam a necessidade de desenvolvimento de sistemas e websites adequados para estes dispositivos. Nestes termos, o presente texto apresenta os resultados de uma pesquisa sobre o emprego do design de interface no desenvolvimento de um projeto de website para a Faculdade de Administração de Artes de Limeira, FAAL, com adequações para a visualização em tablets, em específico para o Ipad.
\end{abstract}

interface design, mobile applications, tablets, web design

The instant access to information and development of mobile communication technologies causes an enhancement of the modes of interactivity. The creation and popularization of the tablets have the need to develop adequate systems and websites for these devices. Accordingly, this article presents the results of a survey on the use of interface design in the development of a website project for the Faculty of Administration and Arts in Limeira, FAAL, with adjustments for viewing on tablets, in particular for the iPad.

\section{Introdução}

O design gráfico tem como objetivo a criação de mecanismos de comunicação capazes de solucionar as necessidades dos seres humanos. Para tanto, o profissional desta área precisa compreender o usuário, estudar suas necessidades e o ambiente onde será efetivado o processo de interação, tendo em vista o projeto de soluções que transmitam o conjunto informacional de modo eficiente.

Esse objetivo toma grande complexidade no mundo contemporâneo, que conectado em rede, possibilita o acesso instantâneo de informações aos seres humanos. Nestes termos, o projeto de websites e sistemas de informação, vêm se expandido e ganhando proporções que exigem o levantamento minucioso de dados, influenciando diretamente no crescimento e divulgação do design de interface ${ }^{1}$.

Quando o design de interface surgiu, sua influência a priori no desenvolvimento de websites, como mecanismos comunicacionais, não foi efetivamente significativa, mas seu alcance tem aumentado, principalmente diante da necessidade de aperfeiçoamento dos projetos para o uso na internet ${ }^{2}$. Hoje os usuários têm exigências em relação à navegação, gerando demanda de criação de projetos informacionais adequados. São necessários construtos ergonômicos que minimizem o estresse navegacional e o usuário nem mesmo perceba tal mecanismo ${ }^{3}$.

\footnotetext{
1 Para Johnson (2001, p.17) "interface" refere-se ao tradutor e mediador da comunicação entre o usuário e o computador, sendo que "para que a mágica da revolução digital ocorra, um computador deve também representar-se a si mesmo ao usuário, numa linguagem que este compreenda".

${ }_{2}^{2}$ Inicialmente os sites possuíam o objetivo de transmitir mensagens e informações (Weinman, 1996, p.29), passando com o tempo a conotar num mecanismo de criatividade de identificação visual e funcional (Bairon, 1995, p.190-191).

${ }^{3} \mathrm{KALBACH}, 2009, \mathrm{p} .21$
} 
Sanches, Tiago Zambuzi; Sniker, Tomas Guner | Design da informação e conteúdo para dispositivos móveis: projeto de website para Instituição de Ensino Superior, IES, adaptado para iPad.

Assim, é imprescindível que esta navegação apresente uma seqüência que o usuário possa compreender ${ }^{4}$. Segundo Kalbach o projeto de um website deve compreender e suprir as necessidades dos usuários, que podem ser classificadas hierarquicamente em: a) disponibilidade; b) usabilidade; c) confiança; e d) desejo $^{5}$, de modo que o levantamento de dados para a elaboração projeto atenda aos pontos principais que devem ser trabalhados, isto é, na elaboração deste prognostico informacional torna-se essencial o levantamento dos objetivos do "sistema web" ${ }^{6}$ e de que modo o mesmo pretende relacionar-se com o usuário ${ }^{7}$.

Além disso, com crescente complexidade dos modos de interatividade e a criação de novas tecnologias de acesso à internet como mobiles, smartphones, tablets etc., torna-se necessário desenvolver sistemas que otimizem a navegação nestes aplicativos. Com base nestas informações, o presente texto apresenta os resultados de uma pesquisa sobre o levantamento de dados e desenvolvimento de projeto de website para a Faculdade de Administração de Artes de Limeira, $\mathrm{FAAL}^{8}$, com adequações para a visualização em tablets, em específico para o $\operatorname{Ipad}^{9}$, segundo os preceitos do design de interfaces.

\section{Método}

A pesquisa foi subdividida em etapas tendo em vista o processo de conceituação e fundamentação metodológica. A etapa inicial tratou do levantamento de material bibliográfico relacionado à área do de design de interfaces. Na sequência, analisou-se o site da FAAL, que estava no ar, segundo os preceitos do design de interface. Em seguida, foi traçado o perfil da Instituição, bem como dos seus alunos, levantando dados capazes de influenciar direta ou indiretamente na configuração do website como instrumento educacional, mecanismo de comunicação e ferramenta de marketing. Para tanto, foram elaboradas entrevistas semiestruturadas em profundidade com alunos, professores e dirigentes da Instituição. Nestas entrevistas, foram investigadas as principais demandas em relação ao site, bem como os principais problemas de navegabilidade que deveriam ser sanados no novo projeto.

$\mathrm{Na}$ etapa seguinte, foram analisados sites de Instituições de ensino renomadas e de tradição no ensino superior, bem como das principais concorrentes da FAAL na região e outros materiais imagéticos e textuais pertinentes ao tema.

Neste projeto aborda-se a adaptação do site da plataforma PC (desktop) para tablets, em específico para o iPad da Apple. Para atingir este objetivo foi realizada uma análise desta plataforma, onde foram levantadas suas principais funções e características, tendo em vista o desenvolvimento do projeto.

\section{Análise de Mercado e Similares}

Para o desenvolvimento prático do projeto, buscou-se compreender características essenciais contidas em um site de ensino superior, delimitando os pontos fortes e fracos segundo o aspecto informacional, estrutural e de adaptação tecnológica.

Conhecendo mais sobre a Instituição e seus principais concorrentes na cidade de Limeira e sua micro-região, foram levantados pontos relacionados ao design dos websites por meio de uma análise de SWOT, e estabelecidas diretrizes para o desenvolvimento do projeto.

Para tanto, foram utilizados conceitos referentes ao design da informação e ergonomia, garantindo que as análises fossem realizadas segundo estes parâmetros, a fim de estabelecer

\footnotetext{
${ }^{4}$ KALBACH, 2009, p.29

${ }^{5}$ CHAK, 2004, p.2

${ }^{6}$ Sistema Web é o termo utilizado para designar, de forma geral, sistemas de informática projetados para utilização através de um navegador, na internet ou em redes privadas

${ }^{7}$ Kalbach (2009, p.175) alerta para a importância deste conceito onde "a intenção e a função da navegação devem ser imediatamente claras, particularmente para sites ricos em informações com objetivos de negócios".

${ }^{8}$ www.faal.com.br

${ }^{9}$ Apesar de recente, o iPad ganhou expressão global, sendo o produto mais vendido da Apple em 2010 e com cerca de 1 milhão de unidades vendidas em 2011
} 
Sanches, Tiago Zambuzi; Sniker, Tomas Guner | Design da informação e conteúdo para dispositivos móveis: projeto de website para Instituição de Ensino Superior, IES, adaptado para iPad.

comparativos entre os sites analisados, destacando os aspectos positivos e negativos de cada um deles.

A partir da análise dos concorrentes e do uso da matriz SWOT ${ }^{10}$, notou-se que os usuários buscam uma visualização clara da marca por meio da sua integralização com o website, sendo que a mesma, além da possibilidade de acesso às redes sociais, deve possuir estrutura leve e atualizada, tornando-se um canal direto de comunicação com os usuários (figura 1).

\begin{tabular}{|c|c|}
\hline FORÇA & FRAQUEZA \\
\hline $\begin{array}{l}\text { - Layout c ontemporâneo e atraente; } \\
\text { - Acesso às mídias soc iais; } \\
\text { - Identidade visual integrada. }\end{array}$ & $\begin{array}{l}\text { - Falta de atualização; } \\
\text { - Falta de possibilidades de interação; } \\
\text { - Desorganização das informações; } \\
\text { - Banner em Fash; } \\
\text { - Problemas de funcionamento; } \\
\text { - Links quebrados; } \\
\text { - Falha de program ação; } \\
\text { - Upload demorado; } \\
\text { - Resolução inadequada. }\end{array}$ \\
\hline OPORTUNIDADES & AMEAÇAS \\
\hline $\begin{array}{l}\text { - Posicionamento de mercado; } \\
\text { - Oportunidade de inovação; } \\
\text { - Diferenciação dos concorrentes; } \\
\text { - Maior atratividade e interatividade } \\
\text { com mídias soc iais; } \\
\text { - Aplicação para iPad e mo biles; } \\
\text { - Melhorar a performance nas } \\
\text { ferramentas de SEO; } \\
\text { - Facilitar o processo de atualização } \\
\text { e manutenção do website. } \\
\text { - Situar-se como portal de ac esso a } \\
\text { informaç ões para a comunidade. }\end{array}$ & $\begin{array}{l}\text { - Websites de outras Instituições que } \\
\text { tem uma equipe para manutenção e } \\
\text { atualização; } \\
\text { - Lançamentos de novas tecnologias } \\
\text { que se não ac ompanhadas podem } \\
\text { tornar o site mais desatualizado; } \\
\text { - Aperfeiçoam ento dos websites de } \\
\text { outras instituições. }\end{array}$ \\
\hline
\end{tabular}

Figura 1: análise SWOT do website da FAAL

A compreensão de tais aspectos permitiu a identificação de parâmetros iniciais para o desenvolvimento de uma estrutura interativa, com navegabilidade bem resolvida e adaptada para o dispositivo tablet.

\section{Levantamento de dados}

A etapa do levantamento de dados iniciou-se com a elaboração de uma entrevista junto à direção da Instituição, onde foram delimitados os objetos iniciais e os principais problemas percebidos no website que estava no ar naquele momento.

A coleta de dados ${ }^{11}$ e sua interpretação de modo a criar uma estrutura básica, reduzindo assim os erros metodológicos, estratégicos e processuais é um processo fundamental. A entrevista realizada com os diretores apontou exigências relacionadas à facilitação do acesso de informações aos usuários. Além disso, notou-se preocupação com a criação de um visual que representasse credibilidade. Nas respostas, destacou-se também a necessidade de manter as mesmas áreas de informação já existentes no atual website (figura 2), sendo elas: cursos, vestibulares, institucional, vídeos, avaliação do MEC e fale conosco. Também foram

\footnotetext{
${ }^{10}$ SWOT é a sigla inglesa para Forças (S), Fraquezas (W), Oportunidades (O) e Ameaças (T), sendo uma importante ferramenta para análise ambiental - tanto interna quanto externa - que através da dinâmica das organizações e do mercado (VALUE BASED MANAGEMENT, 2007).

${ }^{11}$ Segundo Munari (2008), "a análise de todos os dados recolhidos pode fornecer sugestões acerca do que não deve-se fazer para projetar bem uma luminária, e pode orientar o projeto de outros materiais, outras tecnologias, outros custos"
} 
Sanches, Tiago Zambuzi; Sniker, Tomas Guner | Design da informação e conteúdo para dispositivos móveis: projeto de website para Instituição de Ensino Superior, IES, adaptado para iPad.

especificadas áreas que deveriam ter especial destaque devido à sua importância parra o projeto pedagógico da Instituição.

Figura 2: Home Page da Faculdade de Administração e Artes de Limeira.

Disponível em: http://www.faal.com.br

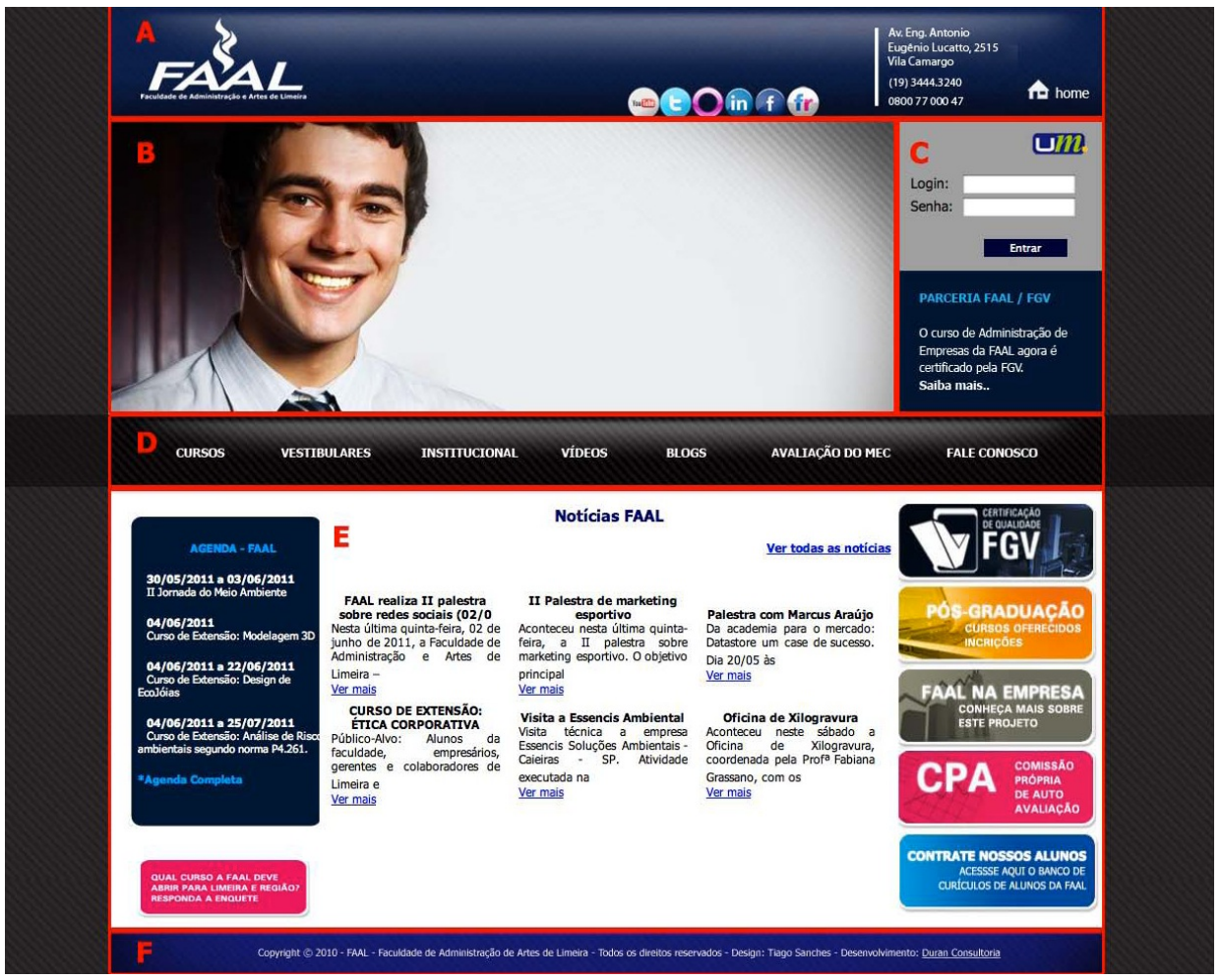

A segunda etapa da coleta de dados compreendeu o levantamento sobre o perfil dos alunos. Dentro do processo do projeto é essencial após a definição do problema, ser realizada a coleta de informações, para que possa-se aprofundar o conhecimento sobre aquilo que será trabalhado. Neste momento deve-se procurar por referências e soluções desenvolvidas por outros designers, pois antes de verificar qualquer solução, é melhor verificar se alguém já trabalhou isto (MUNARI, p.40).

A importância de conhecer o perfil do público-alvo (usuário), reflete diretamente em questões ergonomicas e visuais do layout, como cores, tamanho de fontes, uso de imagens e mecanismos de comunicação, apropriados ao grupo em questão implicados na navegabilidade e usabilidade do website.

\section{Desenvolvimento}

Com base no levantamento de dados, deu-se início ao esboço do grid, que caracteriza-se como uma estrutura que mapeia o espaço das informações, como guia para a elaboração do design de interface ${ }^{12}$, como as margens das telas e barra de ferramentas, barra de navegação ou a barra do próprio browser, além de áreas de informação e estruturas complexas de títulos, subtítulos, autores, listagens e link ${ }^{13}$.

${ }^{12}$ TONDREAU, 2009, p.08

${ }^{13}$ TONDREAU, 2009, p.60 
Portanto, no desenvolvimento do grid (figura 3), além da organização e harmonização dos blocos informacionais a serem utilizados, delimitou-se as dimensões que irão fazer parte de cada elemento do website como um todo. Adotou-se a dimensão de 940 pixels, visto que tal dimensão maximiza a aplicabilidade do website tanto em microcomputadores e notebooks, quanto nos tablets.

Figura 3: Grid do website

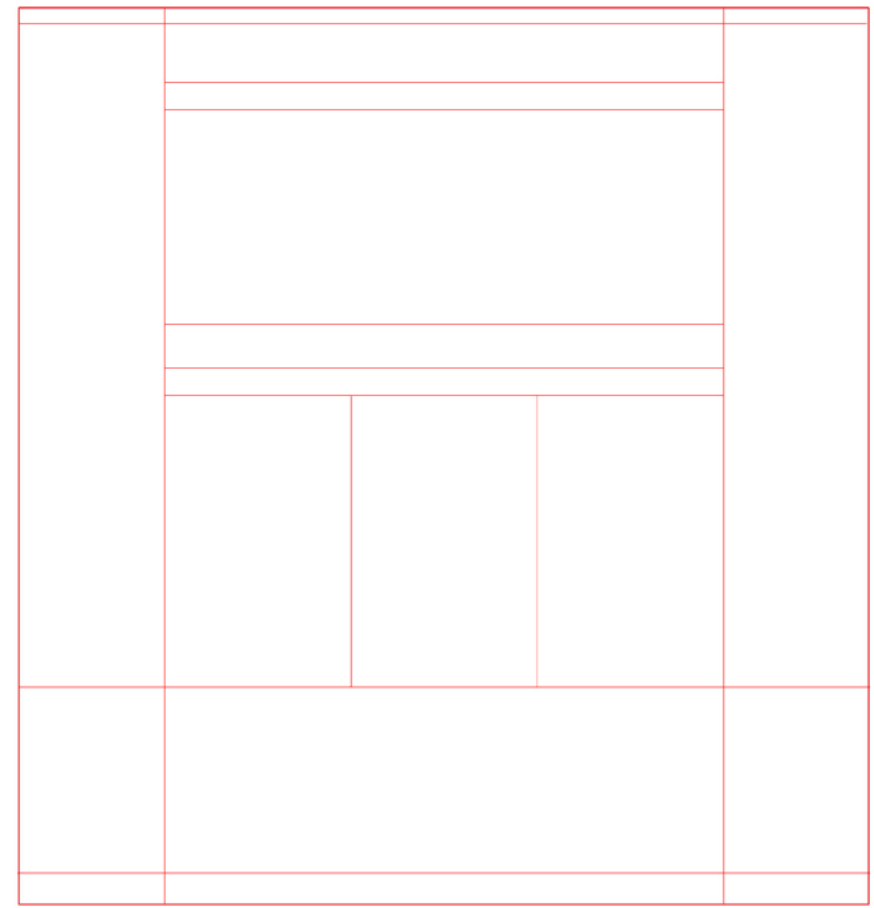

Porém, esboçar os blocos de informação não é o ponto chave da construção de um website voltado ao design de interface, antes é preciso que sejam compreendidos os grupos informacionais a serem utilizados, sendo necessário, elaborar o mapa do site, isto é, uma forma estrutural de conjuntos de informações que objetivem facilitar a navegação dos usuários ${ }^{14}$.

Segundo Kalbach (2009, p.292) o mapa do site é uma forma clássica de explorar estruturas alternativas e comunicar a arquitetura para os outros, facilitando a navegação e estrutura das informações. Utilizando uma estrutura hierárquica pode-ser ver os níveis de disposição em um relacionamento pai-filho, também denominado como estrutura em árvore, devido as suas ramificações. Com o uso das facetas, categorias que oferecem maior flexibilidade ao organizar a informação, agrupou-se todo o conteúdo em sete áreas principais, todas abaixo de uma página pai (home). Cada uma dessas áreas tem suas filhas, formando uma estrutura não muito complexa, de fácil localização, com fluidez no processo de assimilação do conteúdo informacional. Na próxima etapa aplicaremos esta relação de informação em aplicação a um processo que culminará no layout.

${ }^{14} \mathrm{KALBACH}, 2009$, p.292 
Sanches, Tiago Zambuzi; Sniker, Tomas Guner | Design da informação e conteúdo para dispositivos móveis: projeto de website para Instituição de Ensino Superior, IES, adaptado para iPad.

Figura 4: Mapa do Site

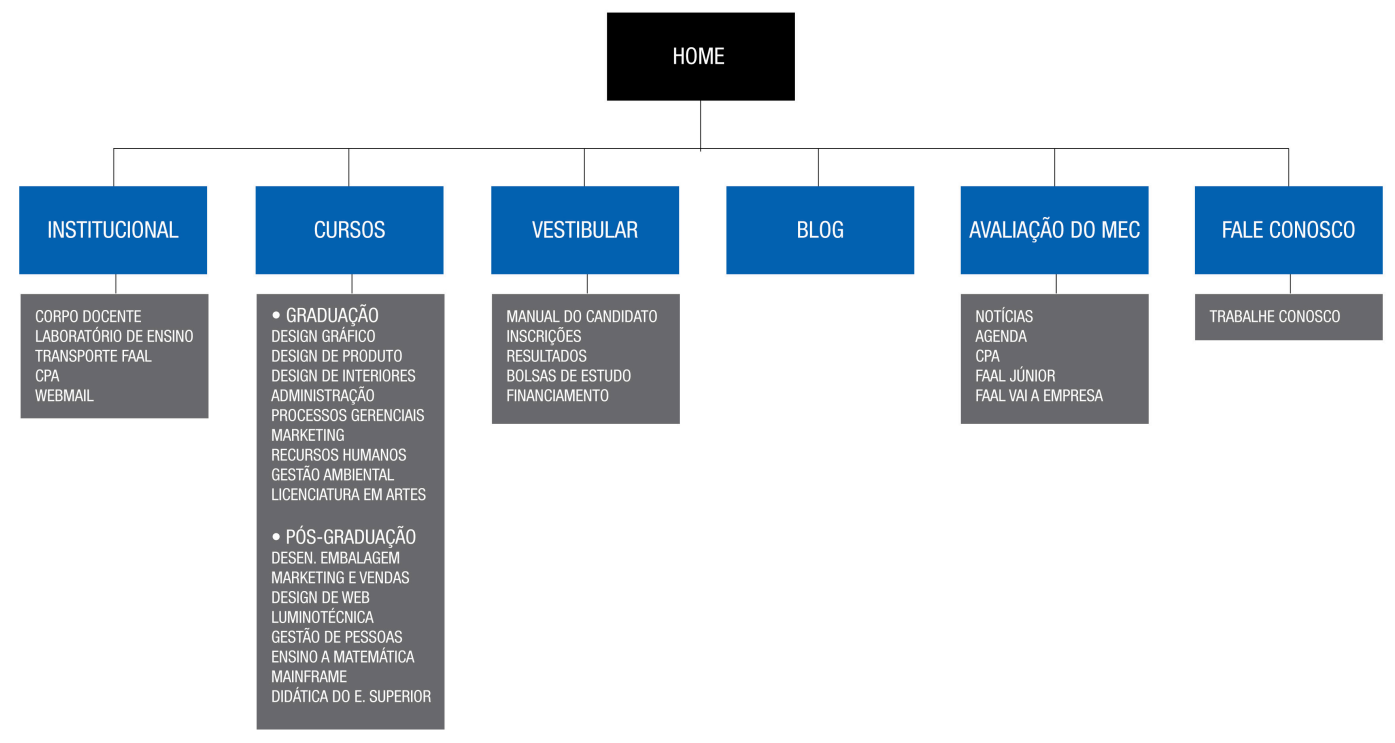

Este conjunto informacional aplicado à estrutura pré-definida do site proporciona e embasa a criação do wireframe ${ }^{15}$, isto é, permite o desenvolvimento de um esboço do layout final do site com o objetivo de corrigir possíveis falhas na estrutura de forma a evitar correções, alterações e reparos no layout.

Concluída esta etapa, o wireframe (figura 4) foi apresentado a um grupo composto por funcionários, professores, alunos e dirigentes da Instituição com objetivo de adequá-lo. $\mathrm{Na}$ sequencia, iniciou-se o desenvolvimento do layout considerando todos os seus elementos tipografia, imagens, paleta de cores, desempenho etc.

No desenvolvimento do layout deve-se projetar uma identidade única e hierarquizada das informações, de forma que os usuários possam compreender a identidade visual sem que haja perda navegacional como pode-se notar na figura 6.

Figura 4: Estrutura do pré-site

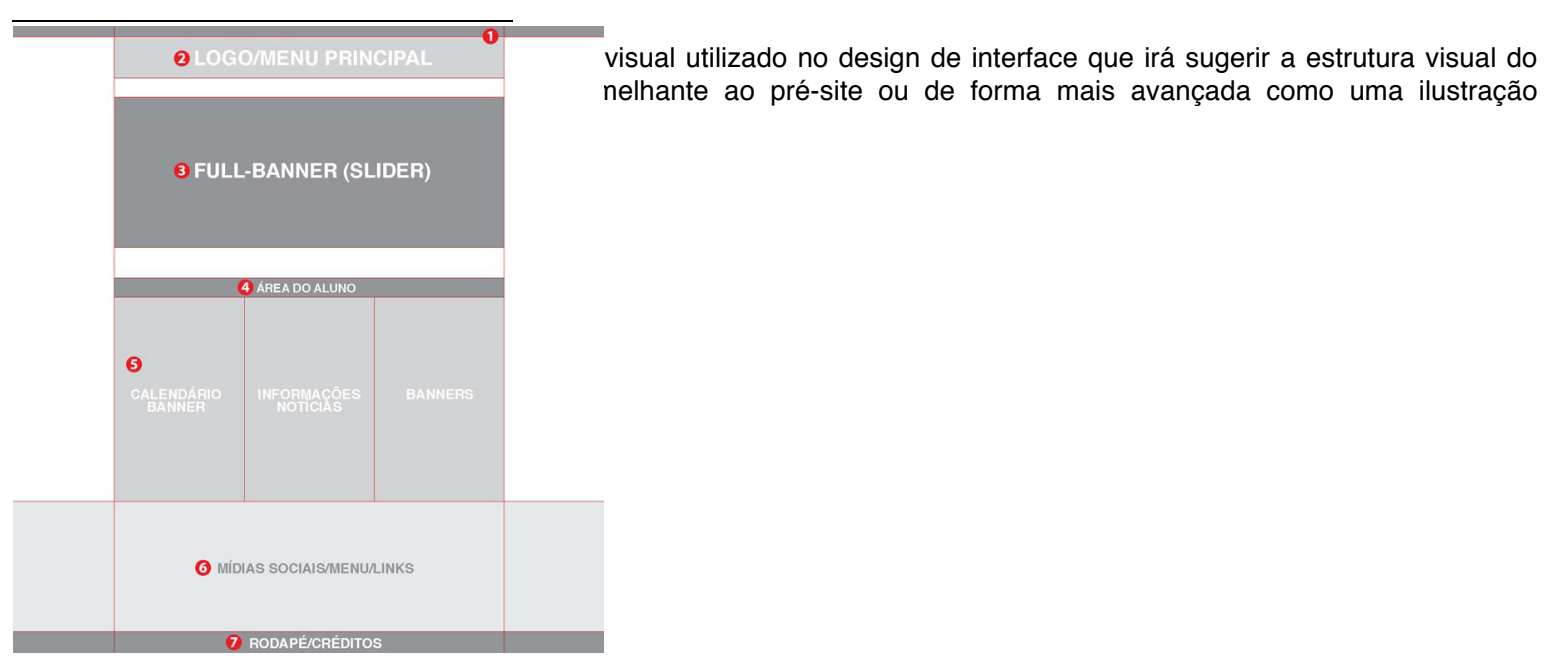


Sanches, Tiago Zambuzi; Sniker, Tomas Guner | Design da informação e conteúdo para dispositivos móveis: projeto de website para Instituição de Ensino Superior, IES, adaptado para iPad.

Figura 5: Estrutura do wirefrime (completo)

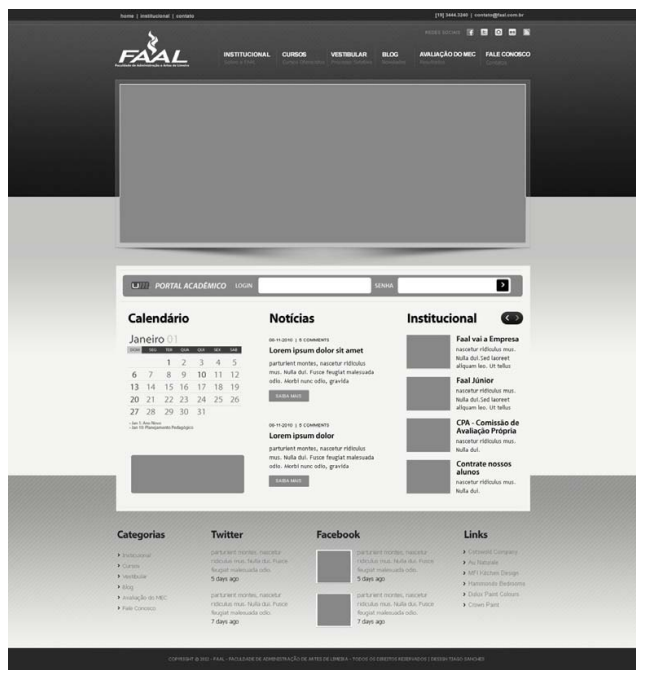

Dessa forma, elementos como paleta de cores e tipografia fazem-se fundamentais para a compreensão dos níveis hierárquicos e organizacionais do site ${ }^{16}$, além de agregarem maior qualidade a interface gráfica.

Com o grid definido e o pré-site já estabelecido em módulos, iniciou-se a criação do layout do site propriamente dito, contudo, deve-se atentar ao fato de que este projeto concebe a adaptação para a plataforma iPad. Conforme pode-se ver (Figura 5) as principais áreas de informações ficam a disposição do usuário. Devido ao tamanho da área de informações, ainda resta uma boa área para o background, que mantém perfeitamente a uniformidade visual entre o site acessado em um computador, quanto pelo iPad, trabalhando o máximo de compatibilidade e garantindo a mesma interface gráfica entre as duas plataformas.

O iPad não faz uso do mouse, pois o sistema touch screen permite ao usuário navegar pelo aparelho por meio do toque. Todavia, os dedos de uma pessoa são maiores que as setas de um mouse, portanto, deve-se ter em mente que links, elementos de navegação e botões precisam ser claros e grandes facilitando o toque e acesso as informações. Além disso, no caso da tipografia utilizada em websites, recomenda-se o uso famílias tipográficas sem serifa, garantindo maior legibilidade ao usuário, pelo corpo, peso e facilidade de visualização das mesmas no monitor (FARIAS, 2001, p.72). É fundamental que seja desenvolvida a diferenciação visual por meio de fontes não serifadas e do uso de diferentes corpos e pesos da família tipográfica — regular, bold, itálico, sublinhado.

Por este motivo, adotou-se para este projeto a família tipográfica Myriad, uma fonte sem serifa, desenvolvida por Robert Slimbach e Carol Twombly por meio da Adobe Systems, sendo similar a fonte Frutiger. Em 1988, a Adobe criou a Myriad Pro, uma extensão desta família, que inclui variações como a versão condensed, extended, light e bold, tornando-a uma fonte versátil. Além disto, é uma fonte padrão de várias plataformas, funcionando perfeitamente tanto em PC's como em MAC's, além de dispositivos como o iPod e o iPad facilitando a adaptação do layout. Para facilitar o processo de programação do website, fez-se necessário a padronização do tamanho e pesos das fontes sendo utilizado a Myriad Pro Bold 30 para todos os títulos, Myriad Pro Semibold 18 para subtítulos e Myriad Pro Regular 13 para o corpo do texto, o que garantia boa legibilidade em ambas as plataformas, principalmente pelo fato de que o iPad pode sofrer reduções no tamanho da tela caso ela esteja em seu modo de visualização vertical (960x1024). Desta forma, os tamanhos e pesos variam determinando as informações em destaque e facilitando o processo de identificação do usuário, impactando significativamente na navegabilidade.

O design de interface deve também considerar as influencias das cores e suas aplicações nas relações cognitivas dos usuários. No caso das aplicações no site proposto à $F A A L$, o emprego da cor azul deve-se a sua a predominância na identidade visual da empresa.

\footnotetext{
${ }^{16}$ LUPTON, 2006, p.99
} 
Sanches, Tiago Zambuzi; Sniker, Tomas Guner | Design da informação e conteúdo para dispositivos móveis: projeto de website para Instituição de Ensino Superior, IES, adaptado para iPad.

Finalizada esta etapa, o layout foi novamente submetido a um teste com alunos, professores, funcionários e diretoria da Instituição. Feitos os ajustes necessários, iniciou-se o desdobramento do layout, aplicando-o nas páginas internas. Observa-se abaixo o resultado final desta etapa (Figura 6).

Figura 6: Layout da página Institucional

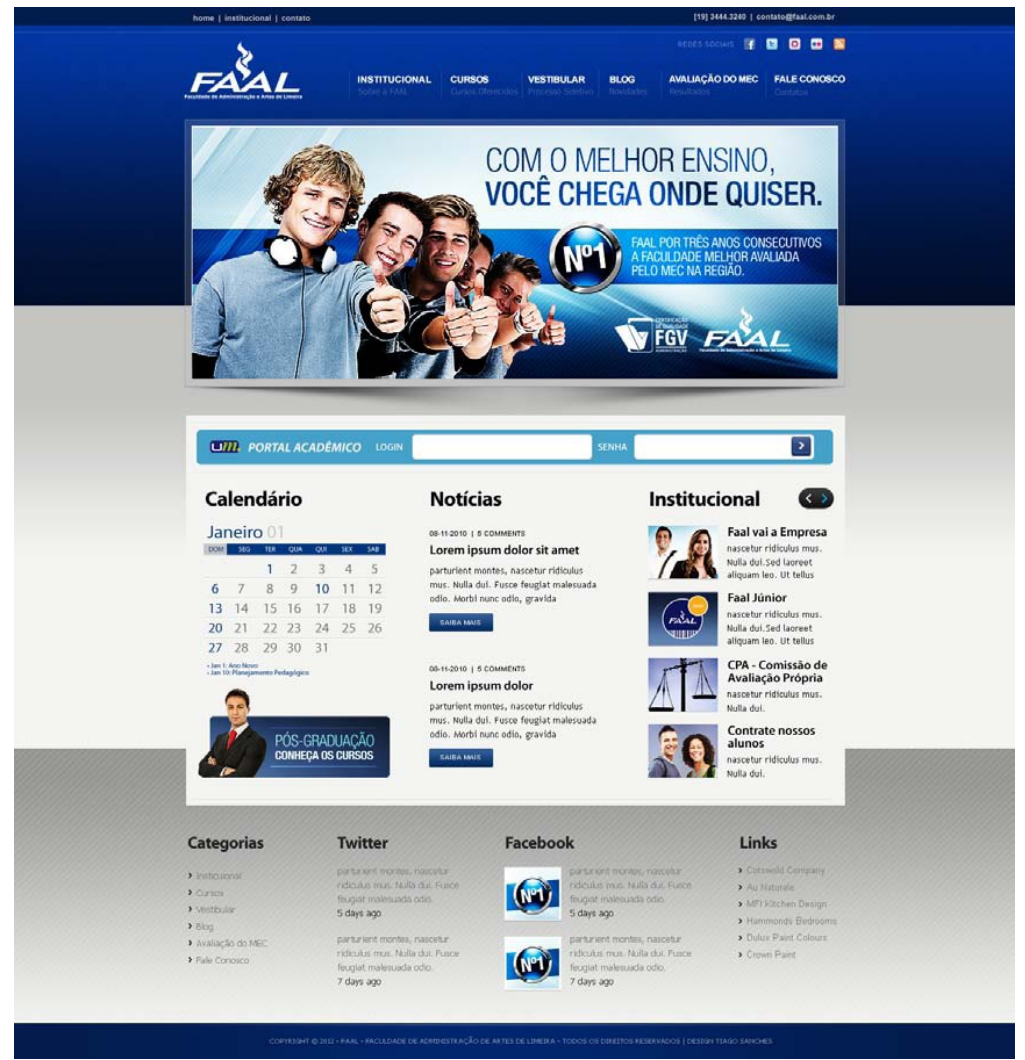

Para cada uma das páginas internas (institucional, cursos, vestibular e etc.) utilizou-se cores diferentes, a fim de distinguir as áreas uma das outras, facilitando a localização e o acesso, assim como a orientação de navegação, proporcionando uma mudança visual que alerta a troca de área e conteúdo.

Outro item fundamental na estruturação dos desdobramentos refere-se à necessidade de menus laterais - situados à direita - que facilitam na busca de informações sobre cada grupo e área de saber do sistema web, de forma que seis áreas foram desenvolvidas derivadas da Home Page: institucional, área de cursos, vestibular, blog, avaliação do MEC e fale conosco.

O iPad tem seu uso baseado em diferentes tipos de toque para diversos comandos (toque duplo, toque com 4 ou 5 dedos, manter pressionado). Destacam-se também os movimentos de deslizar e arrastar (swipe), importante em aplicativos (apps) de revistas e jornais. Além do movimento de "pinça", aonde se juntam e afastam os dedos para o zoom in e zoom out.

Este projeto preocupa-se em atender tais possibilidades postas pela plataforma e orientar a navegação, bem como indicar ao usuário onde ele deve tocar, conteúdo multimída (áudio e vídeo) e interatividade. Contudo, como este layout atende tanto a demanda Desktop quanto ao iPad, levou-se em conta que, acima de tudo, este projeto é de um website e deve atender as orientações e estruturas pré-determinadas a web, além de garantir facilidade de navegação aos tablets. 
Sanches, Tiago Zambuzi; Sniker, Tomas Guner | Design da informação e conteúdo para dispositivos móveis: projeto de website para Instituição de Ensino Superior, IES, adaptado para iPad.

Entretanto, a criação dos grupos e a aplicação da ergonomia na estruturação de seus layouts não corresponde a máxima da proposta apresentada: a interatividade com o iPad. Para tanto, no desenvolvimento dos layouts foram considerados os aspectos navegacionais do tablet, desde as dimensões da página até os seus recursos - ícones, botões, entre outros.

Após o teste de funcionalidade com o uso do aplicativo Adobe Device Central CS5.5, que possui um simulador da interface deste produto da Apple, observou-se que o layout e suas visualizações satisfizeram as necessidades desta interface tanto com o equipamento na posição vertical, como horizontal ${ }^{17}$ (Figura 7 ).

Figura 7: Visualização do Layout no iPad 1024x768 pixels (horizontal) e 768×1024 pixels (vertical)
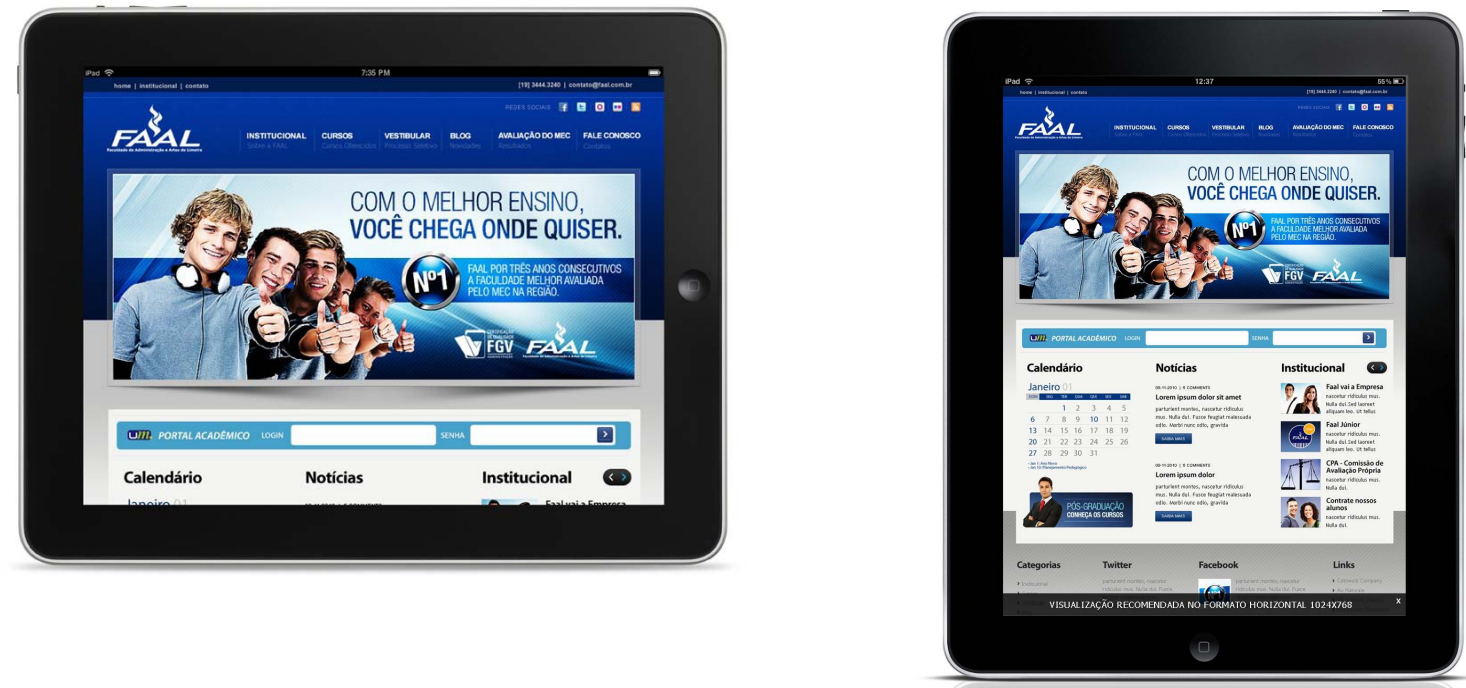

\section{Resultados}

Com intuito de quantificar a qualidade do projeto desenvolvido faz-se necessário mensurar o grau de satisfação e melhorias obtidas no ponto de vista dos usuários beneficiados pelo trabalho realizado, a saber: alunos, funcionários, professores e comunidade local. Desta forma, foi utilizada como fonte de coleta de dados, uma pesquisa quantitativa para mensurar de forma numérica e estatística os resultados, garantindo por meio de uma amostragem a opinião do público-alvo sobre o projeto. Assim, aplicou-se um questionário com 10 questões referentes ao design da interface como: layout, diagramação, usabilidade, interatividade e inovação. Esta pesquisa foi aplicada a um grupo 285, composto por membros da comunidade, alunos e ex-alunos da Instituição.

Após a aplicação desta pesquisa utilizando o método de Gale ${ }^{18}$ - que por meio de perguntas fechadas considera o perfil de qualidade percebida - observou-se que cerca de $90 \%$ dos usuários se adaptaram ao layout com relação à tipografia, imagens e navegabilidade, e afirmaram encontrar com facilidade as informações. Os participantes também consideraram o novo layout mais atraente que o anterior, principalmente por sua interação com as redes sociais e suas aplicações aos tablets, além de agregarem credibilidade à Instituição.

\footnotetext{
${ }^{17}$ O iPad possuí um dispositivo conhecido como "acelerômetro", um sensor gravitacional que detecta o movimento da tela, onde o conteúdo será adaptado para o versão vertical e horizontal.

${ }^{18}$ BRANDALISE, p. 10
} 
Sanches, Tiago Zambuzi; Sniker, Tomas Guner | Design da informação e conteúdo para dispositivos móveis: projeto de website para Instituição de Ensino Superior, IES, adaptado para iPad.

\section{Referências}

2011, o ano dos tablets. Disponível em: http://mundomovil.3gamericalatina.com/ptbr/content/2011-o-ano-dos-tablets. Acesso em: 23/03/2011.

BRANDALISE, Loreni Teresinha. Modelos de Medição de Percepção e Comportamento. Disponível em: <http://www.lgti.ufsc.br/brandalise.pdf> Acesso em: 18 nov. 2011.

CHAK, Andrew. Como criar sites persuasivos. São Paulo: Makron Books, 2004.

CHURCHILL, Gilbert A. Marketing: criando valor para os clientes. São Paulo: Saraiva, 2000.

DRANE, Robert E. apud, CHURCHILL, Gilbert A. Marketing: criando valor para os clientes. São Paulo: Saraiva, 2000.

FARINA, Modesto. Psicodinâmica das cores em comunicação. São Paulo: Edgar Blucher, 1986.

FREITAS, Daniel Leal. Guia completo de Wireframing. Disponível em: http://www.novaz.com.br/blog/2010/11/guia-completo-de-wireframing. Acesso em 10/10/2011.

HOLLIS, Richard. Design gráfico: uma história concisa. São Paulo: Martins Fontes, 2000.

JOHNSON, Steven. Cultura da Interface: como o computador transforma nossa maneira de criar e comunicar. Rio de Janeiro. Jorge Zahar Ed, 2001.

KALBACH, James. Design de navegação web. Porto Alegre: Bookman, 2009.

LUPTON, Ellen. Pensar com tipos: Guia para designers, escritores, editores e estudantes. Tradução: André Stolarski. São Paulo: Cosac Naify, 2006.

LYNCH, Patrick e Sarah Horton. Web Style Guide: Basic Design Principles for Creating Web Sites. New Haven: Yale University Press, 2001.

MUNARI, Bruno. Das coisas nascem coisas. São Paulo: Martins Fontes, 2008.

NIELSEN, Jakob. Designing web usability. California: New Riders, 2000.

STRUNCK, Gilberto. Viver de design. Rio de Janeiro: 2AB, 2007.

TONDREAU, Beth. Criar grids: 100 fundamentos de layout. São Paulo: Editora Blucher, 2009.

Webmastering - ergonomia de um site web. Disponível em: http://pt.kioskea.net/ contents/web/ergonomie.php3. Acesso em: 16/05/2011

WEINMAN, Lynda. Designing WEB Graphics 2. California: New Rider, 1996.

VALUE BASED MANAGEMENT. Management Methods. Disponível em: http://www.valuebasedmanagement.net. Acesso em: 04/11/2007

Tiago Zambuzi Sanches, Possui graduação em Design Gráfico: Comunicação Visual pela Faculdade de Administração e Artes de Limeira (2011). Atualmente é diretor de arte - Plenna,sim. Tem experiência na área de Desenho Industrial, com ênfase em Desenho Industrial

$<$ tiago@tiagosanches.com.br >

Tomas Guner Sniker, Doutorando em Design e Arquitetura pela Faculdade de Arquitetura e Urbanismo da Universidade de São Paulo, Fau-Usp. Mestre no programa de pós-graduação em Artes Visuais da Escola, Eca-Usp. Atualmente é professor e coordenador do curso de Design da Faculdade de Administração e Artes de Limeira, Faal. Na mesma instituição, coordena também o curso de pós-graduação em Desenvolvimento Gráfico de Embalagens.

< designcoordena@faal.com.br > 